\title{
Organization of People and Materials Delivery by Suspended Diesel-Hydraulic Transport in the Mines of JSC "SUEK-Kuzbass"
}

\author{
Vadim Gornostayev ${ }^{1}$, and Sergey Kubrin ${ }^{2}$ \\ ${ }^{1}$ JSC SUEK-Kuzbass, 652507 Leninsk-Kuznetskiy, ul Vailieva, bld.1, Kemerovo region, Russia \\ ${ }^{2}$ The Institute for the Study of Complex Mineral Development, Russian Academy of Sciences, \\ 111020 Kryukovskiy toupik, bld. 4, Moscow, Russia
}

\begin{abstract}
In the effective operation of a mining enterprise, the function of supplying production sites plays a decisive role. The use of highperformance extraction areas in coal mines has changed the requirements for auxiliary transport. The use of modern heavy-duty process equipment, especially in longwall mining systems, requires an increase in the capacity of the routes for delivery and transportation. The main components of the auxiliary transport are related to the technical capabilities of the locomotives, technological and technical condition of the suspension road, organizational issues regarding the placement of intermediate transshipment points and the human factor. To determine the issues that need to be addressed, the article analyzes the experience of using suspended diesel - hydraulic transport in the mines of JSC "SUEK Kuzbass". The tasks and ways of their solution have been determined.
\end{abstract}

\section{Introduction}

The history of the appearance of suspension monorail transport in the company JSC "SUEK - Kuzbass" goes back to 2005. The first locomotives were Ferrit LSP-70DO which were used locally, since there was no developed network of the monorail road at that time. By 2008, diesel transport almost completely replaced the high-risk and traumatic tail-rope haulage. However, there was no repair base, maintenance specialists; and major system solutions in the organization of diesel transport were not found. Long-term repairs of locomotives, their ineffective use that manifested itself in frequent downtime, failures, breakdowns, etc., became more frequent. In 2014 JSC "SUEK-Kuzbass" decided to transfer the entire diesel-powered fleet to the production unit "Spetsnaladka" and to create a workshop for qualified repair of locomotives.

\section{Materials and Methods}

To date, the division has been established that is responsible for logistics and deliveries management in the mines. For accident-free operation, separate sections for repair, maintenance and use of suspended diesel-hydraulic locomotives have been created. This 
decision was justified by the fact that investing in diesel-hydraulic transport did not justify itself, often the cost of repairs and maintenance of various coal-mining enterprises differed significantly. When the entire diesel fleet was handed over to the production unit Spetsnaladka, the condition of the former was as follows: out of 85 transferred machines, 25 were not suitable for operation, at the moment out of the remaining 60 vehicles, 14 were included in the disposal plan for 2017; in 2015, 4 new locomotives were purchased. As a result, by mid- 2017 almost $75 \%$ of diesel-hydraulic locomotives will exhaust their motor resources. In this connection, there was a need to find solutions to improve and optimize the deliveries by suspended diesel-hydraulic transport in the mines of JSC "SUEK-Kuzbass". The lack of a systematic approach and efficient organization of logistics does not allow increasing the locomotives utilization factor is above 0.37 .

To solve all the problems described above, JSC "SUEK-Kuzbass" developed a program for development of diesel-hydraulic transport in the mines, which includes thirteen areas:

1. Estimation of the need for locomotives permanently located in the mine for current operations.

2. A group of locomotives moved from to mine for the period of dismantling-assembly operations.

3. A replacement locomotive delivered to the operation for the time of major repairs of the locomotive.

4. Auxiliary equipment (lifting devices, containers, passenger cars, rock dusting machine).

5. Means of cargo attachment, slinging and lashing.

6. Establishment of the monorail road installation unit.

7. The widespread use of automatic switch points, the expansion of the network of filling stations.

8. Transfer of delivery men from mines to "Spetsnaladka". Correction of the wage system with respect to the amount of freight transported.

9. The practical training program for newly employed drivers.

10. Re-equipment of diesel hydraulic locomotives in pantograph.

11.Training for operating and maintenance personnel.

12. Equipping diesel locomotives with data transmission and positioning systems.

13. Organization of production of connecting rods for diesel hydraulic locomotives.

The main target is to optimize the operation of diesel-hydraulic transport, which includes the division of the main fleet of locomotives into permanent operating units according to the production program at the production unit of JSC SUEK-Kuzbass, units movable from mine to mine for the period of assembly and dismantling operations, and replacement locomotives (back-up) for prompt replacement of the failed ones, which can be repaired in the shop, and not in the mining conditions (Table 1, 2).

Table 1. Loco distribution by mines (January-June).

\begin{tabular}{|c|c|c|c|c|c|c|}
\hline Mine & January & February & March & April & May & June \\
\hline Ruban & 8 & 8 & $8 / 2$ & $8 / 2$ & $8 / 2$ & 8 \\
\hline 7 November & $3 / 1$ & $3 / 1$ & $3 / 1$ & 3 & 3 & 3 \\
\hline Kirov & $10 / 3$ & $9 / 3 / 1$ & 10 & 10 & 10 & 11 \\
\hline Komsomolets & 5 & $5 / 1$ & $5 / 1$ & 5 & 5 & 5 \\
\hline Polysaevskaya & 5 & 5 & 5 & 5 & 5 & 5 \\
\hline Yaleevskogo & 5 & 5 & 5 & 5 & 5 & 6 \\
\hline
\end{tabular}




\begin{tabular}{|c|c|c|c|c|c|c|}
\hline Kotimskaya & $6 / 1$ & $6 / 1$ & $6 / 1$ & 6 & 6 & 6 \\
\hline T-3 1 & 7 & 7 & $6 / 1$ & 7 & 7 & 6 \\
\hline T-3 2 & $6 / 1$ & 7 & 7 & $6 / 1$ & 7 & 7 \\
\hline
\end{tabular}

Table 2. Loco distribution by mines (July-December).

\begin{tabular}{|c|c|c|c|c|c|c|}
\hline Mine & July & August & September & October & November & December \\
\hline Ruban & 8 & $8 / 9 / 1$ & $8 / 2$ & $8 / 2$ & $8 / 2$ & $8 / 2$ \\
\hline 7 November & $3 / 1$ & $3 / 1$ & $3 / 1$ & $3 / 1$ & $3 / 1$ & $3 / 1$ \\
\hline Kirov & $10 / 3$ & 10 & 10 & 10 & 10 & $10 / 2$ \\
\hline Komsomolets & 5 & $5 / 1$ & 5 & $4 / 1$ & $4 / 1$ & 5 \\
\hline Polysaevskaya & 5 & $5 / 2$ & $4 / 1$ & 5 & 5 & 5 \\
\hline Yaleevskogo & 5 & $5 / 1$ & 5 & 5 & 5 & 5 \\
\hline Kotimskaya & $6 / 1$ & 6 & 6 & 6 & 6 & 6 \\
\hline T-3 1 & 7 & 7 & 7 & 7 & 7 & $6 / 1$ \\
\hline T-3 2 & $6 / 1$ & 7 & 7 & 7 & 7 & 7 \\
\hline
\end{tabular}

In order to analyze the throughput capacity of the monorail suspension road in the mines, calculations were made for delivery of materials and equipment along the routes, based on the dependences obtained in the study [1-10]. The bottlenecks were identified, which were broken down into component routes with the organization of overload sites for increasing the capacity.

Due to the increase in cargo flows in the mines and the increase in capacity of the technological mining equipment used, stops caused by faults in the monorail road have become frequent. Currently, M155 profile is used, which ceases to meet safety requirements due to a mismatch between its bearing capacity and breaking force and the goods being transported and the use of more powerful locomotives. Therefore, everywhere in all mines it is planned to replace it with a more powerful profile M200.

\section{Results and Discussion}

Intensification of delivery operations requires the commitment of staff. For this purpose, the system for assessing the work performed has been developed, in which the motivation of the staff is a first-priority task. Basically, the accepted assessment of the work performed is of interest to the personnel in overcoming the longest distance in the shift with the load, while the concept of "cargo" is governed by four states, as well as the maximum use of machine availability time in the conduct of large-scale diesel locomotive work.

\section{Conclusion}

The actual problem of staff non-competence required the development of the program of training and practical skills development. One of the solutions is the creation of a training ground at the operating mine with the introduction of a diesel-hydraulic locomotive, using 
the DLZ130F as an example, which makes it possible to clearly monitor the correctness of the actions of the diesel locomotive operator, as well as establish speed limits, etc. Modern requirements of safety rules call for search of solutions for transportation safety, one of the solutions is the reconfiguration of the suspension locomotive with the constant presence of the driver's cab in the head of the train, as well as the conversion of locomotives to the ground ones with the manufacture of the floor mounted rack road at "Spetsnaladka".

In total, in order to ensure the efficient use of the existing diesel-hydraulic transport fleet, the proposed set of measures makes it possible to increase the utilization rate of suspended diesel-hydraulic locomotives.

\section{References}

1. Yu. I. Kutepov, N. A. Kutepova, Geoecologia, 5, 405-413 (2003)

2. Instructions on the methods of hydrogeomechanical justification of optimal parameters of hydro dumps and dumps on weak grounds. Part II. The rationale for the optimal parameters of the dumping structures (VNIMI, Leningrad, 1998)

3. Regulations for the protection of structures and natural objects from harmful influence of underground mining in coal deposits (Nedra, Moscow, 1981)

4. V. N. Gusev, A. S. Mironov, D. A. Ilyukhin, The method for determining the height of the zone of water-conducting cracks over the mined out space in the reservoir deposits Patent No 2477792. 20.03.2013, No 8 (Rospatent, Moscow, 2013)'

5. Yu. I. Kutepov, N. A. Kutepova, M. A. Karasev, A. D. Vasilieva, Hydrogeomechanical processes in development of spoil dumps and hydraulic fills (EUROCK 2018, Saint Petersburg, 2018)

6. V. V. Zubkov, I. A. Zubkova, Zones of technogenic water-conducting cracks by roomand-pillar mining (EUROCK 2018, Saint Petersburg, 2018)

7. V. V. Zubkov, I. A. Zubkova, International Research Journal, 2.05(59), 172-175 (2017)

8. V. N. Gusev, Geomechanics of technogenic water-conducting cracks (Mining, St.Petersburg, 1999)

9. A. G. Akimov, Geomechanical aspects of rock subsidence due to underground development of coal and ore deposits (Mining, St.-Petersburg, 2013)

10. A. M. Galperin, Hydrogeology and Engineering Geology: Geotechnika - Selected Translations of Russian Geotechnical Literature (CRC Press, New York, 2003) 